\title{
The Problem of Methodological Future Primary School Teacher Training in a Digital Educational Environment
}

\author{
Ranija R. Khamatvalieva* (a), Vera K. Vlasova (b) \\ (a), (b) Kazan Federal University, 420008, Kazan (Russia), 18 Kremlyovskaya street, ranijaz@rambler.ru
}

\begin{abstract}
This article deals with the problem of the future primary school teacher methodological training against the backdrop of the global education and the world economy digitalization. According to theoretical analysis research a number of Russian and foreign scientists has identified factors facilitating and impeding the effective methodological training of a future primary school teacher in an education digitalization.
\end{abstract}

Keywords: methodological teacher training, methodological competence, digital literacy, digital competence, education digitalization, digital generation divide, distance learning, practice-oriented approaches in education.

\section{(C) 2020 Ranija R. Khamatvalieva, Vera K. Vlasova}

This is an open access article distributed under the terms of the Creative Commons Attribution License (CC BY 4.0), which permits unrestricted use, distribution, and reproduction in any medium, provided the original author and source are credited.

Published by Kazan federal university and peer-reviewed under responsibility of IFTE-2020 (VI International Forum on Teacher Education)

\footnotetext{
* Corresponding author. E-mail: ranijaz@ rambler.ru
} 


\section{Introduction}

The changes in the current socio-economic environment and the modernization of the world and Russian education systems are creating new requirements for educational policy that should meet the current needs of the state and the society. Considering the changing paradigm of education, there is an urgent need for the society and the state to prepare students - future teachers for professional activities in an education digital environment.

While the Federal State Educational Standards (2016) reflect requirements for educational outcomes, educational technologies, educational content structure and educational process conditions, digital generation, modern digital technologies and a rapidly developing digital economy dictate their conditions for training teachers.

Despite the higher education evolution there are no links between the new teacher training trajectory, the new training structure, the forms and methods of teaching students.

Analysis of psychological-pedagogical and scientific literature revealed contradictions in university training of the future teacher today. In conditions of education technologization and digitalization there are contradictions between:

- accelerated introduction of digital technologies in the university educational process and the shortage of specialists involved in the future teachers training with corresponding digital competences;

- orientation of the modern education system towards the future teacher training and the challenges that arise here and now, the solution of which cannot be postponed;

- increasing personal requirements of the future teacher and his psychological unpreparedness for professional activity due to the digital divide and the low level of digital competence;

- increasing need to improve practical approaches in the future teachers training and desire to transfer individual disciplines or entire training courses to distance learning.

The problem research of future primary school teachers methodological training in the context of digitalization in Russia and abroad will reveal the gaps in the primary school teachers professional training 
today. The results of this theoretical study may serve as a basis for further theoretical and empirical research in the future primary school teachers professional training.

To identify the factors influencing the effectiveness of future primary school teachers methodological training in the digital educational environment, we have applied a theoretical analysis method.

In order to identify distance learning advantages and disadvantages, a comparative analysis method of classroom and distance learning elements was applied.

Our choice of research methods was based on the purpose and objectives of the study.

\section{Purpose and objectives of the study}

Purpose of the study is to identification of factors influencing the quality of future primary school teachers methodological training in the modern digital educational environment.

The main objectives were identified as follows: disclosure of methodological training features of future primary school teachers, study of Russian and world experience in the use of digital educational tools, analysis of aspects of the digital educational environment development in Russia and abroad, identification of factors influencing the effectiveness of the future primary school teacher methodological training in the digital educational environment.

\section{Literature review}

The theoretical and methodological basis of research was world-oriented and psychological-pedagogical investigation in the field of the future teacher professional training and digital transformation of the state, society, economy and education.

Analysis of psychological, pedagogical and scientific literature has shown that in today's scientific space a sufficient number of studies devoted to the current problem of teacher training in modern education transformation.

Among them we will highlight the works on education informatization and education transformation in the context of digitalization (Mavlyutova, 2018); Nikulina \& Starichenko, 2018); Dneprovskaya, 2018); Klochkova \& Sadovnikova, 2019), general problems of primary school teacher professional training (Pavlova et al., 2018; Baklanova, 2018; Ignatova, 2019; Vergeles \& Granichina, 2018), methodical problems of primary school teacher training (Tsareva, 2016; Azizova, 2018). 
The most valuable for our research results were the works devoted to:

- application of web-based educational technologies in teacher training (Vezirov \& Kostina, 2016; Smolyaninova \& Bezyzvestnykh, 2019);

- use of educational platforms (Shakirova \& Sabirova, 2018);

- advantages and disadvantages of distance learning (Kuznetsova, 2015);

- features of future primary teachers training to design web-based lessons (Kuznetsova, 2018);

- advantages of using mobile technologies at school lessons (De Jong et al., 2018);

- designing of e-learning resources different types (Kuznetsova \& Yankina, 2018; Tukenova et al., 2019);

- using e-learning resources experience (Tukenova et al., 2019; Makarova et al., 2017);

- using e-assessment in higher education (Pashkova, 2016; Bubnov et al., 2015).

\section{Methodology}

Today the future teachers professional training is under close attention of the state and the society. And the problem of future teacher methodological training has always been one of the leading ones for pedagogical education.

The primary school teacher methodological training is the mastering of methods and technologies in special courses teaching subjects. The result of methodological training is a specialist who knows the training methods and technologies. Under the future teacher methodological training Tsareva (2016) means mastering the methods and technologies of teaching subjects in the study of special courses, which names in the curricula of different universities are "Mathematics teaching methods (Russian language, literature, literary reading, basics of natural science, etc.)," or "Mathematics training methodology (Russian Language, Literature, Literary Reading,...," or "Primary mathematics education methods (Russian Language, Literature,...", or "Theory and methodology of training...," or "Theories and technologies of training...."

In the teacher methodological training, there are theoretical and practical parts. The theoretical part of the future primary school teacher pedagogical preparation includes theoretical courses knowledge which form the basis of school and interdisciplinary subjects. 
The most important part of the methodology is the practical training of the future teacher. Practical training of the future teacher is an essential part of the teaching. Practical teacher training is training that provides practical knowledge of pedagogical activity components, readiness to solve pedagogical tasks in real conditions of educational process. Obtaining high-quality practical training during the educational programme is the most important motivational factor for successful job placement in a profession.

The main purpose of the future teacher's methodological training is to teach the specifics of working with children in the process of studying a particular subject, the formation of their subject and methodological knowledge and skills, practical skills in school. It should be noted that methodological training is based on the readiness, ability and desire of the student to accept the knowledge. Thus, professional predisposition, internal motivation and psychological readiness are the foundations of methodological training.

Today, the Russian pedagogical education system is on the way of searching for the optimal model of universal teacher training. That is why the primary task of Russian education is to ensure the quality training of the specialist ready to work with the digital child, the representative of the generation of socalled "digital natives".

Representatives of the modern generation $\mathrm{Z}$ are children of multimedia technologies. These are people who were born in the information society and from an early age gained access to the Internet, YouTube, and various gadgets. In another way, representatives of $\mathrm{Z}$ generation are called "Digital Native", and representatives of the generation preceding them are called "Digital Immigrant", since in their childhood there was no free access to the Internet, there were no digital technologies. This so-called "digital divide" of generations is the subject of research by a number of scientists (Shcherbina \& Kislov, 2020; Miroshkina, 2017; and others). However, psychological studies of this phenomenon are very limited to date. According to Soldatova and Rasskazova (2016 a), the "digital divide" construct is a kind of "black box" that creates the illusion of explanation but does not currently have a psychological content. Optimal ways to cope this digital generation divide have not been developed.

The current generation of children and adolescents are very digital people. However, they are better in technology than in human behavior and emotions. They are alien to live communication, they feel comfortable themselves only behind the screens of smartphones, tablets and computers. Along with digital literacy the younger generation is one-dimensional. "One-dimensional man", who is a representative of the digital age, was first described in the book of Herbert Marcuse (1964). According to Marcuse (1964), the modern common man is a man dependent on mass media and television, a man with no personal point of view, ruled from outside. Kugay and Mikhailova (2019) draw attention to the mental features of the 
modern digital generation. According to researcher, modern generation is characterized by the lack of detailed speech (chopped phrases inherent in social networks), inability to remember large texts, perception of information mainly through pictures, poor memory, distracted attention, hearing loss. Unlimited access to information gives them confidence in their views which are not always correct. Today parents and teachers are less and less authoritative for children. Now the Internet is the authority to which you can turn for any information.

In order to work effectively with modern generation of "digital natives," the teacher must have not only "digital literacy", but also digital competencies. The term "digital literacy" was first introduced in 1997 by Paul Gilster (1997). He defined digital literacy as the ability to understand critically and use computergenerated information in various formats from a wide range of sources. Martin and Madigan (2006) elaborated on this definition. By digital literacy they meant the awareness, attitudes and ability of individuals to make appropriate use of digital tools and tools to identify, access, manage, integrate, assess, analyse and synthesize digital resources; building new knowledge systems, as well as communicating with others for constructive social action in the context of specific life situations.

Many scientists are researching digital competence and trying to create its optimal model. Soldatova and Rasskazova (2016 b) propose their concept of digital competence which is a part of social competence and includes four components (knowledge, skills, motivation and responsibility) implemented in different spheres - work with content, communications, technosphere and consumer sphere.

Definitely, the technical capacity of higher education institution plays an important role in the training of the future specialist. Mavlyutova (2018) speaking about digital transformation pays attention not only to technical resources re-equipment, but also to human potential reset and all internal processes optimization of an educational institution. Mavlyutova (2018) considers extremely important to provide training, retraining and specialists teaching, including heads of organizations on core competencies in the field of digitalization.

The current state of distance education in Russia requires special attention. The percentage of online education in the Russian educational market is low: $1.8 \%$ for higher education programmes and $6.7 \%$ for supplementary vocational education. The largest percentage of students (82\%) studying exclusively by distance education is from commercial universities (Dneprovskaya, 2018).

In order to identify distance learning advantages and disadvantages in the process of future primary school teachers methodological training, let's analyze the Table 1, where we will reveal and compare the elements of classroom training (full-time, part-time, full-time/part-time learning) and distance learning. 
Table 1. The comparative analysis of classroom and distance learning elements

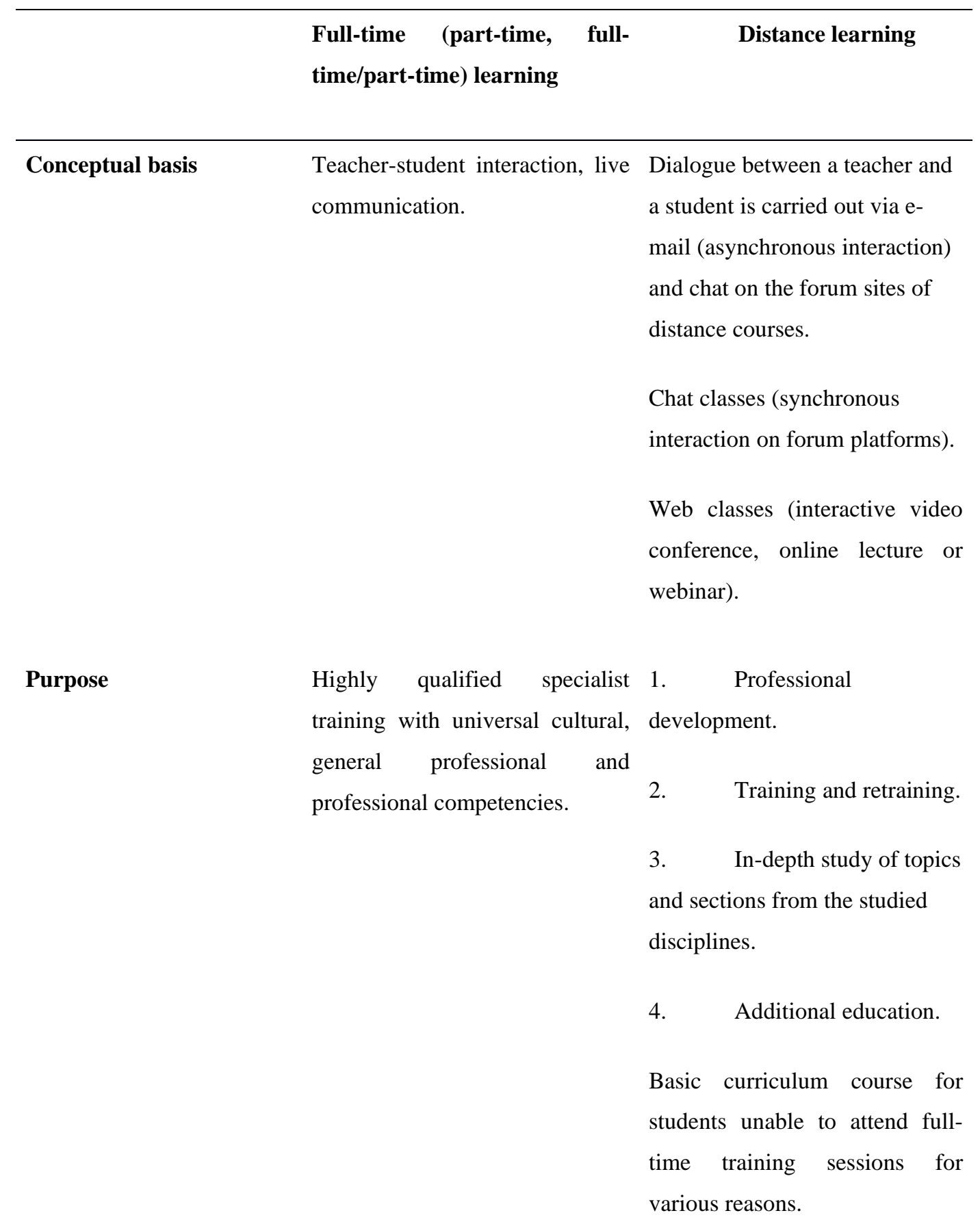



Learning material volume The learning material volume is A large amount of learning limited. material.
It depends on the number of Free choice of studied sources of hours allocated for lectures and information. practical exercises, as well as for independent work.
Methods and forms of Listening, comprehension, Individual independent work of students' activity exercise, study of textbooks and a student with educational primary sources, modeling, material. including practical work, educational research.
Individually, in pairs, in small groups, frontally.
Methods and forms of Traditional (lectures, Online lectures (webinars). teaching proseminars, seminars, special seminars, colloquiums, laboratory work, workshops and special practices, etc.) and non- traditional forms of classes.
Active, interactive learning methods.

The role of the teacher in Provider of continuous cognitive Students coordination. the learning management activity of students, their process independent work, scientific creativity. 


\section{Controlling diagnostics educational process}

and Oral, written, practical control. Regulated written and machine the

Possibility of individual control.

\author{
Systematic, regular monitoring \\ at all stages of the learning \\ process. \\ Control is comprehensive, makes \\ it possible to test theoretical \\ knowledge, intellectual and \\ practical skills.
}

Undoubtedly, nothing can replace the live communication of a teacher and a student that is a huge advantage of classroom activities. In addition, these classes have several important functions that cannot be implemented remotely:

1) current control of students ' independent work results;

2) students' skills in independent oral reports, justifying and defending their own point of view;

3) teaching students the rules of discussion and listening to a partner;

4) identification of individual learning difficulties in individual students, possible shortcomings of their thinking or some mental operations (analysis, synthesis, generalization, abstraction, etc.);

5) identification of students' personal characteristics that can positively or negatively affect the entire learning process and therefore require registration or even correction.

Positive aspects of distance learning are:

1. A large amount of learning material.

Through distance learning students are able to get knowledge from the latest sources in the process of their own research and learning. 
2. Independence, self-control, individualization of education.

The digital age requires individuals to develop self-organization and self-motivation skills, and this is facilitated by individualization of education. Optimization of students' independent work has always acted as a reserve for improving the higher education efficiency. Students acquire the skills of independent planning and organization of their own educational process, that ensures a painless transition to continuous postgraduate education (primarily self-education) upon completing their university study. Independent work makes it possible to reduce the negative effect of certain individual students' characteristics (for example, inertia, inability to distribute attention, inability to act in a situation of time limit, etc.) and maximize the strengths of individuality due to the independent choice of time and methods of work. Access to education from anywhere in the world. Lifelong education is becoming the norm, as online training is actively developing and society's attitude to the learning process is changing.

\section{Results}

\section{Factors contributing to effective of future primary school teachers methodological training in education digitalization}

1. The university's digital education environment containing a full range of ICT tools and systematically using them in accordance with FSES requirements.

2. Practices bases equipped with modern technical training facilities.

3. Digital competence high level among the professionals involved in the future primary school teachers training.

4. Improved practice-oriented approaches in future primary school teachers training using modern digital educational tools.

\section{Obstacles to effective future primary school teacher methodological training in education digitalization}

1. A stable foundation of educational culture, formed over the decades, poorly digitalized and preventing the rapid introduction of technologies into the educational process.

2. Doubts about the efficiency and appropriateness of digital technologies.

3. Poor technical equipment of university informatization services and practices bases. 
4. Ineffective use of digital tools, communication channels, social networks for educational purposes.

5. Inefficient use of distance learning courses potential.

6. Insufficient digital literacy and digital competence low level among the staff involved in the educational process.

7. "Digital divide" of generations.

\section{Discussions}

Is it sufficient to identify the factors influencing the training quality of future teachers to build an effective training trajectory of highly qualified specialist in the education digitalization? The results of this theoretical study do not allow us to give a clear answer to this question.

Since theoretical analysis is most often an integral part of any scientific study and appears as its first stage, the study may be considered incomplete. However, our findings may serve as a basis for further theoretical and empirical research on the future primary school teachers vocational training in the context of educational transformation.

\section{Conclusion}

This research revealed the factors contributing to the effective primary school teachers methodological training. However, there are also obstacles to this process. And, it is worth admitting, against the background of the dynamic global digital economy, the process of education digitalization is at the beginning of its way.

Higher education institutions that train future teachers have a lot of work to modernize the main practiceoriented approaches using modern digital educational tools. Of course, modern technical equipment of educational institutions plays an important role in the formation of future specialists' digital competence. It concerns not only universities, but also the practices bases. It is also worth noting the need for regular updating of technical equipment funds. However, regular ICT further education courses for teachers and educational institutions employees at all levels, the necessary of educational and methodological support on ICT implementation in the educational process would be a huge digital leap for the informatization of Russian education. In a quickly changing digital world it is important to be constantly improved, to meet rapid changes. 
Distance learning is extremely popular today. And this is the most important drawback, since not every profession can be mastered remotely. A teacher is such profession. Considering the specific nature of the primary school teachers training, there is a question about the appropriateness and logic of distance learning introducing into teacher training process. Blended learning is the most successive in the primary school teachers professional training. The combination of classroom activities and e-learning can be highly effective. Comparative analysis of distance learning and traditional classroom learning, scientific literature theoretical analysis led us to conclude, that distance learning can only supplement basic education and not replace it. It is worth noting the main reason why the effectiveness of the future teacher training remotely is questioned: impossible to work with the student's personality.

The digital age is a new stage of human development and is perceived as something inevitable. The Internet today is not only a specific sphere of human activity. The digital world is changing human life and activity, and therefore there is a need to study the processes taking place in it. Political, social, ethical, and psychological processes taking place in the digital world are inextricably linked to all areas of our life, and we unwittingly become users of all the benefits that modern technologies provide us. Owing to digital technologies the scientific world is globalizing, and academic mobility is actively developing.

\section{References}

Azizova, K. M. (2018). The development of subject-methodological competence of primary school teachers as a condition for the quality of professional training of a specialist in a continuing education system. Science and Education, 6(18), 133-135.

Baklanova, G. A. (2018). Pedagogical practice on the organization of extracurricular activities of primary school children as a condition for immersion of future primary school teachers in the profession. World of science, culture, education, 2(69), 242-244.

Bubnov, G. G., Pluzhnik, E. V., \& Soldatkin, V. I. (2015). Criteria for assessing quality in e-learning. Cloud of science, 2(4), 530-543.

Shakirova, G., Sabirova, E. (2018). Using educational websites and platforms in Russia: Cognitive needs of children and problems of teachers. In International Conference on Innovative Technologies and Learning, 91-100. Springer, Cham. DOI: 10.1007/978-3-319-99737-7_9

Shcherbina, E. Y., \& Kislov, A. G. (2020). To pedagogy of the digital divide era. Vocational education and labor market, 1(40), 49-59. DOI: 10.24411/2307-4264-2020-10105 
Smolyaninova, O., Bezyzvestnykh, E. (2019). Implementing teachers' training technologies at a Federal University: E-portfolio, digital laboratory, PROLog module system. International journal of online and biomedical engineering, 15(4), 69-87. DOI: 10.3991/ijoe.v15i04.9288

Soldatova, G. U., \& Rasskazova E. I. (2016 a). The digital divide and intergenerational relations of parents and children. Psychological Journal, 37(5), 44-54.

Soldatova, G. U., \& Rasskazova, E. I. (2016 b). Models of digital competence and online activities of Russian adolescents. National Psychological Journal, 2(22), 50-60.

De Jong, D., Grundmeyer, T., \& Anderson, C. (2018). Comparative study of elementary and secondary teacher perceptions of mobile technology in classrooms. International Journal of Mobile and Blended Learning, 10(1), 12-33. DOI: 10.4018/IJMBL.2018010102

Dneprovskaya, N. V. (2018) Assessment of the readiness of the Russian higher education for the digital economy. Statistics and Economics, 4, 16-28.

Federal State Educational Standard of Higher Education, 2016, http://fgosvo.ru/fgosvo/92/91/4/94

Gilster, P. (1997). Digital Literacy. New York: Wiley and Computer Publishing.

Ignatova, O. I. (2019). Stages of professional development of primary school teachers in teaching activities. World of science, culture, education, 1(74), 241-242.

Klochkova, E. N., \& Sadovnikova, N. A. (2019). Transformation of education in the conditions of digitalization. Open education, 23(4), 13-22. DOI: 10.21686/1818-4243-2019-4-13-22

Kugay, A. I., \& Mikhailova, V. V. (2019). "Digital Generation": Threats and Hopes in the Era of Information-Digital Civilization. Administrative Consulting, 7(127), 90-99. DOI: 10.22394/17261139-2019-7-90-99

Kuznetsova, N. V. (2018) Future elementary school teachers training in lesson designing based on web technology “teaching puzzles electronic design wizard”. Perspektivy Nauki i Obrazovania, 4(34), 123-127.

Kuznetsova, N. V., \& Yankina, L.A. (2018). Approbation and implementation of lesson design technology «Electronic constructor of methodical puzzles» in the educational process. Perspektivy Nauki $i$ Obrazovania, 5(35), 214-220. DOI: 10.32744/pse.2018.5.24 
Kuznetsova, O. V. (2015). Distance Learning: Pros and Cons. International Journal of Applied and Basic Research, 8(2), 362-364.

Makarova, N. N., Chernova, N. V., \& Potemkina, M. N. (2017). Electronic learning resources used in Teacher Education programs for Bachelor's and Master's degrees. Man in India, 97(5), 93-104.

Marcuse, H. (1964). One-Dimensional Man: Studies in the Ideology of Advanced Industrial Society. Boston, MA: Beacon Press.

Martin, A., \& Madigan, D. (2006). Digital literacies for learning. London: Facet.

Mavlyutova, G. A. (2018). Digitalization in a modern higher educational institution. Economic safety and quality, 3(32), 5-7.

Miroshkina, M. R. (2017). Interpretations of the theory of generations in the context of Russian education. Yaroslavl Pedagogical Bulletin, 6, 30-35.

Nikulina, T. V., \& Starichenko, E. B. (2018). Informatization and digitalization of education: concepts, technologies, management. Pedagogical education in Russia, 8, 107-113.

Pashkova, T. S. (2016). Use of electronic systems for monitoring and evaluating students ' knowledge in the computer science lesson. Innovative pedagogical technologies: materials of the V International scientific conference, 129-131. Kazan, Russia.

Pavlova, E. P., Okoneshnikova, N. V., \& Sidorova E. E. (2018). Teaching practices in the professional development of future primary school teachers. World of science, culture, education, 6(73), 183184.

Tsareva, S. E. (2016). Methodological training in the system of professional training of primary school teachers. International journal of experimental education, 12(1), 37-39.

Tukenova, N. I., Mursakimova, G. A., Gruzdeva, M. L., Chetiyeva, K. Z., Elepbergenova, A. U., \& Iskakova, A.A. (2019). Educational multimedia-resources in education. International Journal of Innovative Technology and Exploring Engineering, 8(10), 3617-3620. DOI: 10.35940/ijitee.J9788.0881

Vergeles, G. I., \& Granichina, O.A. (2018) Primary school teacher training: from the beginnings to the future. Bulletin of the Russian State Pedagogical University. A.I. Herzen, 188, 12-21. 
Vezirov, T. G., Kostina, E. A. (2016). Educational web-technologies in training bachelors and masters of pedagogical education. Novosibirsk State Pedagogical University Bulletin, 6(4), 39-49. DOI: $10.15293 / 2226-3365.1604 .04$ 